students, whereby paintings and writing accounts served as facilitating tools, even though teaching students 'non-scientific' subject matter at the beginning of their clinical education might meet with scepticism and cynicism. Our students come from diverse cultural, ethnic and religious backgrounds and include Jews, Arabs; Muslims, Christians and Druze. This presents an additional challenge when using arts that have, by definition, cultural connotations, as an educational tool; paintings depicting patient-doctor interactions are hard to find in Jewish and Islamic culture, due to limited volume of work in the first, and absence in the latter for religious reasons.

The use of painting in teaching reflective competence was well received. Our students found it an innovative and useful educational tool, an exciting 'out of the box' teaching modality.
Moreover, students appreciated the plot, creativity and imagination employed in their fellow students' accounts.

Competing interests None.

Provenance and peer review Not commissioned; externally peer reviewed.

\section{REFERENCES}

1. Rider EA, Nawotniak RH, Smith GD. A Practical Guide to Teaching and Assessing the ACGME Core Competencies. HCPro, Inc, 2007:14-16.

2. Bardes CL, Gillers D, Herman AE. Learning to look: developing clinical observational skills at an art museum. Med Educ 2001:35:1157-61.

3. Dolev JC, Friedlander LK, Braverman IM. Use of fine arts to enhance visual diagnostic skills. JAMA 2001;286:1020-1.

4. Reilly JM, Ring J, Duke L. Visual thinking strategies: a new role for art in medical education. Fam Med 2005;37:250-2.

5. Karkabi K, Cohen Castel 0 . Deepening compassion through the mirror of painting. Med Educ 2006:40:462.

\title{
Insane redemption
}

I believed my sorrows were deep

Thought my anger was justified

Hallucinated that my acts were ordained

Martyr I would be if slain.

Presumed that the colour of battle is bright

Its gilded gold edges embraced me

None shall I spare, it's my destiny

Redemption, restitution, no reconciliation.

Alas I realized it was just a mirage

Wars are always black, pitch black

There's no glory, no martyr, no honour

Just some names on slabs of stone.

The tears that soak your tomb

She and the little ones were dear, so dear

There are no winners or losers in terror acts

Just some utterly shattered souls-departed.

\section{Ajith Cherian}

Department of Neurology, Sree Chitra Tirunal Institute for Medical Sciences and Technology, Trivandrum, Kerala, India

Correspondence to Dr Ajith Cherian, Postdoctoral Fellow in Epilepsy, Department of Neurology, Sree Chitra Tirunal Institute for Medical Sciences and Technology, Trivandrum 695011, Kerala, India; drajithcherian@yahoo.com

Competing interests None.

Provenance and peer review Not commissioned; internally peer reviewed.

Published Online First 4 February 2011

J Med Ethics; Medical Humanities 2011;37:59. doi:10.1136/jmh.2010.006742 